Proceedings of Contemporary Ergonomics and Human Factors 2015: International Conference on Ergonomics and Human Factors,

13-16 April 2015, Daventry, UK.

\title{
THE LIMITATIONS OF USING ONLY CAD AND DHM IN DESIGN RELATING TO HIGH VALUE MANUFACTURING
}

\author{
Teegan L. Johnson and Sarah R. Fletcher \\ Industrial Psychology and Human Factors Group, Cranfield University,
}

The ergonomics suites available within Computer Aided Design and Digital Human Modelling programs are increasingly being used to predict and prevent ergonomic and human factors risk due to poor design. To further aid the reduction in poor design, it is of importance to understand the need for user input and the limitations of these software programs. These limitations include: the small number of available anthropometric population samples; and the disconnect between what a designer perceives as possible, and what is possible within a manufacturing environment. A method of mitigating these limitations is the use of user input using virtual reality suites, mock-ups and motion capture technology.

\section{Introduction}

Poor design for ergonomics has been shown to negatively impact worker health (Broberg, 1997) and workplace performance (Wang and Lau, 2013). As a result the integration of human factors (HF) into the planning process of product development has been identified as a major strategy for mitigating work related injuries and illness (Broberg, 1997). Despite the availability of ergonomic guidelines for engineers (Lehto, Landry and Buck, 2008), ergonomic methods and tools have historically not been available in accessible formats for design engineers, hampering the integration of HF into the design process (Broberg, 1997). The integration of Digital Human Modelling (DHM) and human activity analysis suites into Computer Aided Design (CAD), has given designers access to HF methods and tools (Broberg, 1997). This has led to CAD human modelling tools becoming a common technique for predicting and preventing ergonomic risk within manufacturing (Lockett, Fletcher and Luquet, 2014).

The aim of this paper is to discuss some of the ways HF tools in CAD are used in design and redesign within manufacturing. Some of the issues and limitations that should be considered when using these tools to reduce negative impacts on worker health and performance will be highlighted.

Published by Taylor and Francis. This is the Author Accepted Manuscript issued with: Creative Commons Attribution Non-Commercial License (CC:BY:NC 4.0). Please refer to any applicable publisher terms of use. 


\section{CAD and DHM}

CAD can be used in the design and redesign of structures within manufacturing. Structures are the parts and the framework that holds these parts in place. Within manufacturing these structures tend to be large and occlude operators and their postures, making it difficult to accurately assess for muskulo-skeletal risk. The DHM and ergonomic assessment capabilities in CAD enables the easy variation of anthropometric and biomechanical parameters of virtual manikins (Paul and Wischniewski, 2012). Helping to improve design and usability of products and work systems (Paul and Wischniewski, 2012) by allowing designers to identify how their structure will be used by individuals of different physiologies. Designers can identify how operators will likely interact with their structure; allowing problem areas to be identified such as those that may cause the development of musculo-skeletal disorders (MSD). This reduces the need for large participant pools and mock-ups in the early stages of the design process when assessing structure accessibility. There are however limits in the application of CAD and DHM in practice that should be taken into account.

Designers using DHM to inform their design decisions should be aware of the anthropometric differences between countries (Cavelaars, et al, 2008). CAD programs are limited on the types of pre-set manikins available, which can varied based on the percentiles within the specific populations. However, the number of population groups is limited, meaning that designers looking to develop structures for specific populations not represented in the program will need to identify and interpret the relevant anthropometric data. This requires an awareness of how to manually make changes to the manikins, and create manikins that fit the percentiles of interest; this can be a time consuming process in relation to the ease of use for the preprogramed populations.

When modelling the postures of manikins while interacting with structures, the postures adopted through the task from beginning to end should be modelled. For some activities the working posture may be judged as acceptable by a postural analysis tool; while MSD risk lies in the transition postures. It is therefore of importance that the entire interaction is modelled to identify problem areas. CAD software has the ability to record frame by frame the activity of the manikin and ergonomically assess every frame rapidly (Johnson and Fletcher, 2014), making assessment much faster than traditional forms of postural analysis and allowing the designer to identify exact problem areas in a design.

\section{Operator/user perception and feedback}

$\mathrm{CAD}$ can be used at the start of a project to design a structure and design out obvious problems using DHM and HF tools available. However, input should be gained from individuals outside of the design process to identify the more subtle or missed issues with a design. Ideally this would include representative users. 
An issue with DHM is that it is possible to make a task look feasible that when translated into a manufacturing environment, can only be accomplished with a high level of discomfort. Physical discomfort is indicative of poor biomechanics (Helander and Khalid, 2012) which can contribute to the development of MSD. The movement of a manikin in a CAD program can be limited by fixing the degrees of freedom and applying collision detection to limit unnatural movements. The discomfort levels while completing the task have to be inferred by the designer or engineer. If possible representative users, such as those that will be directly interacting with the structure, should be consulted about perceived discomfort levels of the structure. Virtual reality (VR) and physical mock-ups can be used to gain this information on the accessibility and comfort associated with a structure.

\section{Virtual Reality}

A CAD model can be presented in an immersive VR suite or on a screen and the representative user can either point out where they perceive problem areas to be or physically enact how they would interact with the structure. For individuals physically enacting their interaction, a motion capture (MoCap) suit can be used to capture postures and input that data into $\mathrm{CAD}$. This gives the user visual feedback which can inform their movement and can be ergonomically assessed. This data will be limited because interactions are devoid of tactile information; the structures used for support, guidance or as a barrier are unavailable. However problem areas can still be identified, which can aid in refining the design of the structure. A solution to the need for tactile information is to use mock-ups.

\section{Mock-ups}

Upon the reduction of problems using DHM and VR suites, the structure can be constructed using inexpensive materials with a degree of assembly flexibility. This gives operators a more realistic idea of what interacting with the structure will involve, helping to inform data on physical discomfort. Gaining both the physical movements as well as the qualitative discomfort data involved with interacting with the structure would be advantageous. Discomfort can be used to identify where the structure could be causing stress which may play a role in the development of MSDs (Gielo-Perczak, Karwowski, Hancick, Marras, Karwowski, and Bonato, 2012). A limitation when using mock-ups to gain an understanding of how operators interact with a structure is that the activity of the individual may be occluded. This can make it difficult to pinpoint the exact problem areas on or in the structure that require redesign. Non-optical MoCap suits, particularly where the data can be fed into the CAD program, would allow the whole posture to be captured and translated to a manikin. Problem areas and structures essential for task completion can be identified with the removal of the structures surfaces within CAD. Postural assessment suites within the CAD program can be applied to the data captured giving postural information about the task. 


\section{Conclusion}

CAD modelling with DHM can be used at the start of a design process to improve design and usability. However it is limited to the perceptions of those working on the design, their understanding of how a structure will be implemented and used on a shop floor may be limited. Therefore, representative user input is essential to identify problems that may be missed. User input can be gained through the use of VR and mock-ups to identify physical usability and ease of access for structures along with qualitative comfort data. This information can be used to improve design and help to mitigate work related injuries and stress, helping to reduce cost relating to injuries and improve worker performance.

\section{Acknowledgements}

This work was supported by the UK EPSRC Centre for Innovative Manufacturing in Intelligent Automation.

\section{References}

Broberg, O. (1997). Integrating ergonomics into the product development process. International Journal of Industrial Ergonomics. 19, 317-327.

Cavelaars, A. E. J. M., Kunst, A. E., Geurts, J. J. M., Crialesi, R., Grötvedt, L., Helmert, U., et al. (2000). Persistent variations in average height between countries and between socio-economic groups: an overview of 10 European countries. Annals of Human Biology, 27, 407-421.

Gielo-Perczak, K., Karwowski. W., Hancock, P.A., Marras, W.S., \& Bonato, P. (2012). Multidisciplinary Concepts in Ergonomic Design and Individual Differences in Performance. Proceedings of the Human Factors and Ergonomics Society Annual Meeting, 56, 1034-1038.

Helander M. G. \& Khalid, H. M. (2012). Affective Engineering and Design. In In G. Salvendy (Eds.) Handbook of Human Factors and Ergonomics, Fourth Edition. New Jersey: John Wiley \& Sons, Inc.

Johnson, T. L, \& Fletcher, S. R. (2014). A Computer Software Method for Ergonomic Analysis Utilising Non-Optical Motion Capture. In Sharples, S \& Shorrock, S (Eds.), Contemporary Ergonomics and Human Factors. (pp. 93100). Croydon: CRC Press.

Lehto, M. R., Landry, S.J. \& Buck J. (2008). Introduction to Human Factors and Ergonomics for Engineers. New York: Lawrence Erlbaum Associates

Lockett, H., Fletcher, S., \& Luquet, N. (2014). Applying Design for Assembly Principles in Computer Aided Design to Make Small Changes that Improve the Efficiency of Manual Aircraft Systems Installations. SAE Int. J. Aerosp. 7.

Paul, G., \& Wischniewski, S. (2012). Standardisation of digital human models. Ergonomics, 55, 1115-1118.

Wang, L., \& Lau, H.Y.K. (2013). Digital Human Modeling for Physiological Factors Evaluation in Work System Design. In V.G. Duffy (Eds.), Digital Human Modeling and Applications in Health, Safety, Ergonomics, and Risk Management. Heidelberg: Springer. 
2015-04-13

The limitations of using only CAD and

DHM in design relating to high value manufacturins

Johnson, Teegan L.

CRC Press : Taylor and Francis Group

Teegan Johnson and Sarah Fletcher. The limitations of using only CAD and DHM in design relating to high value manufacturing. Proceedings of the Contemporary Ergonomics and Human Factors 2015: International Conference on Ergonomics and Human Factors, 13-16 April 2015, Daventry, UK.

https://dspace.lib.cranfield.ac.uk/handle/1826/9979

Downloaded from Cranfield Library Services E-Repository 